Idaho National Engineering and Environmental Laboratory

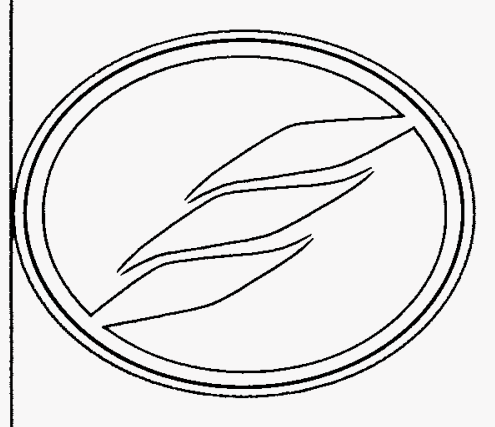

INEELIEXT-98-00898

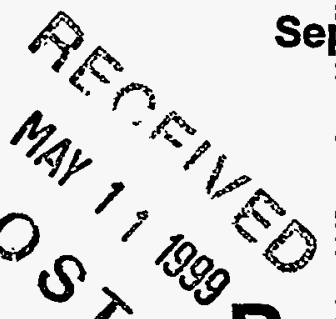

Quality Assurancé Baseline Assessment Report for Los Alamos National Laboratory Analytical Chemistry Operations

R. A. Jordan

LOCKHEED MARTIN 
For additional copies or information on this document, please contact

Chris Ischay

Lockheed Martin Idaho Technologies

P.O. Box 1625, MS 3454

Idaho Falls, ID 83415

Ph. (208)526-4382

Fax (208)526-8878

cpi@inel.gov 


\section{DISCLAIMER}

Portions of this document may be illegible in electronic image products. Images are produced from the best available original document. 


\title{
Quality Assurance Baseline Assessment Report For Los Alamos National Laboratory Analytical Chemistry Operations
}

\author{
R. A. Jordan
}

Published September 1998

Idaho National Engineering and Environmental Laboratory Defense Program Environmental Surety Program Lockheed Martin Idaho Technologies Company Idaho Falls, Idaho 83415

Prepared for the U.S. Department of Energy Office of Defense Programs Under DOE Idaho Operations Office Contract DE-AC07-941D13223 


\begin{abstract}
This report summarizes observations that were made during a Quality Assurance (QA) Baseline Assessment of the Nuclear Materials Technology Analytical Chemistry Group (NMT-1).

The Quality and Planning personnel, for NMT-1, are spending a significant amount of time transitioning out of their roles of environmental oversight into production oversight. A team from the Idaho National Engineering and Environmental Laboratory Defense Program Environmental Surety Program performed an assessment of the current status of the QA Program. Several Los Alamos National Laboratory Analytical Chemistry procedures were reviewed, as well as Transuranic Waste Characterization Program (TWCP) QA documents. Checklists were developed and the assessment was performed according to an Implementation Work Plan, INEEL/EXT-98-00740.

The bases for the assessment were the requirements found in the Department of Energy Carlsbad Area Office and TWCP QA documents (specifically the Quality Assurance Program Document and Quality Assurance Program Plan). In areas where the TWCP requirements were not applicable, good laboratory practices were applied.
\end{abstract}

Several observations were made during the assessment. This report has grouped the specific observations into several general observations and recommendations.

Based upon this assessment, NMT- 1 can plan and implement improvements to the quality management system to meet customer changing needs. Additionally, this assessment will serve as the foundation for achieving certification to analyze samples for the TWCP. 


\section{SUMMARY}

The purpose of this assessment was to evaluate the current status and provide a conduit for implementing improvements to the quality management system in the Nuclear Materials Technology (NMT) Analytical Chemistry Group (NMT-1) at Los Alamos National Laboratory (LANL).

During the course of the assessment many observations were made. This report focuses on the non-compliant observations and those that deviate from good laboratory practices, but it should be noted that several instances of good laboratory practices were observed.

In using the Transuranic Waste Characterization Program (TWCP) Quality Assurance (QA) requirements, as the bases for this assessment, it has been determined that NMT-1 is not prepared to obtain the TWCP certification. This does not indicate that this level of certification is unachievable by NMT-1. With a concerted effort, made by all available resources, NMT-1 could obtain this work as well as other similar projects.

The conclusion made from this assessment was the basic processes and procedures for implementation of better quality operations by NMT-1 are in place. However, the procedures need updating to accurately describe practices at NMT-1. Personnel appear to be open to the development and implementation of an improved process. The management team has begun the work of conveying group expectations, goals, and objectives, but the root of the problem lies in inconsistencies in implementation of the procedures.

These inconsistencies may be due to the recent reorganization and transition from a research and development environment to a more production oriented environment, but it is imperative that these inconsistencies be alleviated, in order for the group to move forward in their improvement effort.

The Idaho National Engineering Laboratory (INEEL) team determined that due to the nature of this assessment, it being a baseline overview, an Action Plan would not be prudent at this time. It is expected that NMT-1 will generate a plan of action for implementation of QA program improvements. 


\section{ACKNOWLEDGMENTS}

The author acknowledges the members of the INEEL Defense Programs Environmental Surety Program (DPESP) Assessment Team, Joan Connolly, Steve McKinney, Robert Thompson, and Don Wood, for providing their support and expertise during all phases of the Quality Assurance Baseline Assessment. 


\section{CONTENTS}

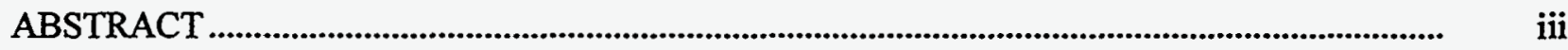

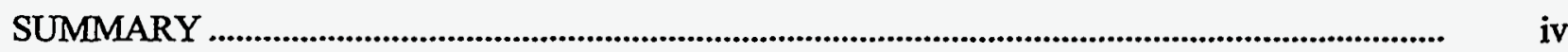

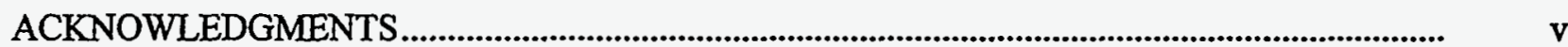

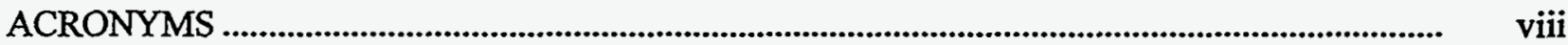

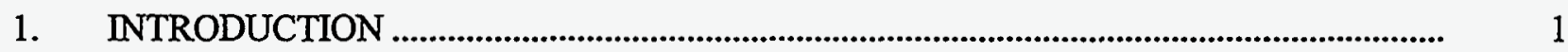

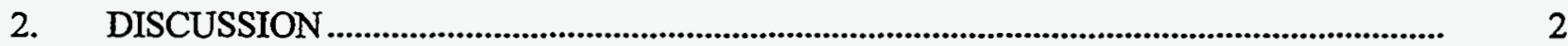

2.1 Organization and Quality Assurance Program .............................................................. 2

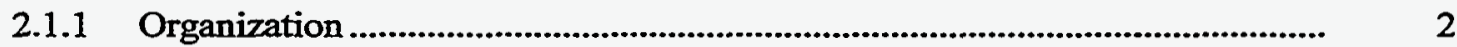

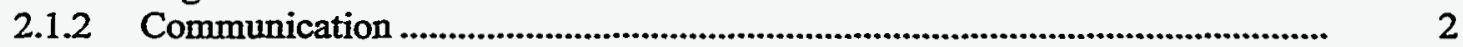

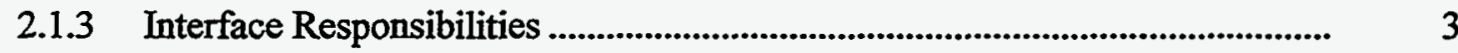

2.1.4 QA Program Documents .......................................................................... 3

2.1.5 Procedures Matrix ....................................................................................... 4

2.1.6 Planning Work.......................................................................................... 4

2.2 Personnel Qualification and Training.................................................................. 5

2.2.1 Qualification and Training ....................................................................... 5

2.2.2 Special Training Requirements ................................................................ 5

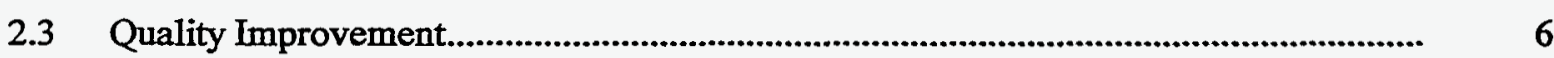

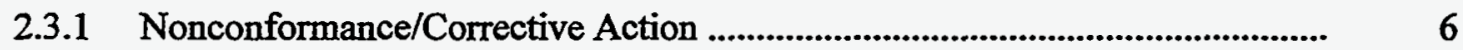

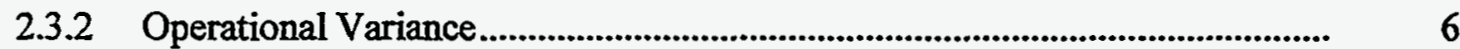

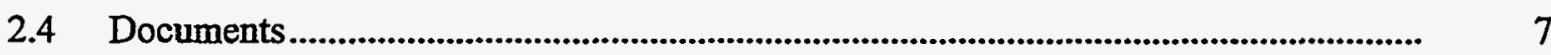

2.4.1 Document Review ........................................................................................ 7

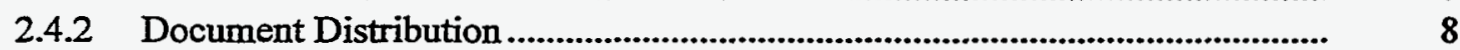

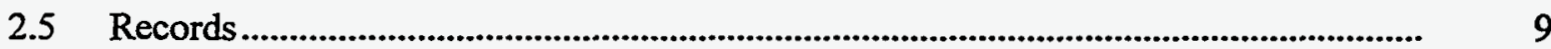

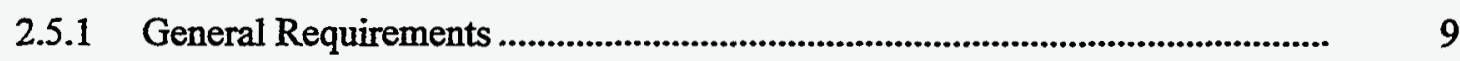

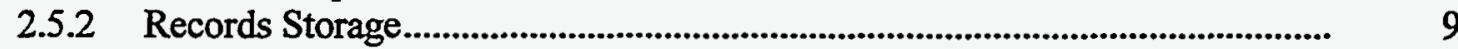

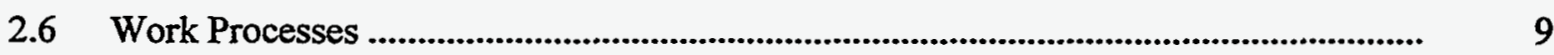

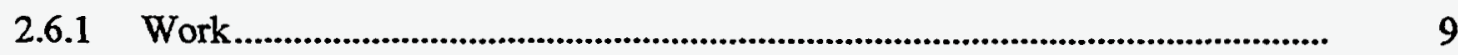

2.6.2 Acceptable Work Performance................................................................... $\quad 10$

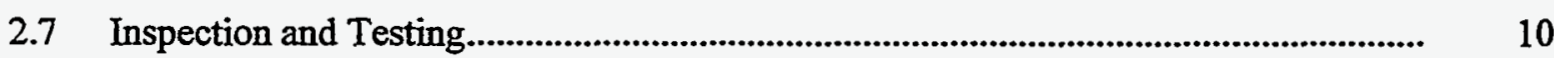

2.7.1 Use and Control of Measuring and Test Equipment (M\&TE) ........................ 10

2.7.2 Calibration of M\&TE .................................................................................. 11 
2.8 Assessment and Oversight........................................................................................

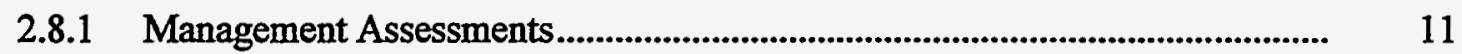

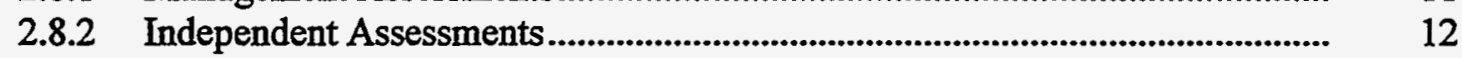

2.9 Sample Management .................................................................................................. 12

2.9.1 Sample Control....................................................................................... 12

2.9.2 Sample Possession/Chain-of-Custody (COC) ................................................ 13

2.9.3 Disposition of Samples....................................................................................... 13

2.10 Data Management..................................................................................................

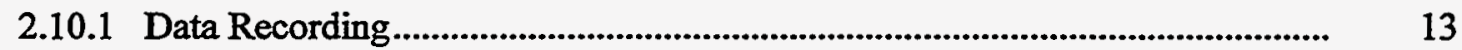

2.10.2 Data Transfer and Reduction.......................................................................... 14

2.10.3 Data Collection, Analysis, and Reporting …………...................................... 14

2.10.4 Data Validation................................................................................................. 15

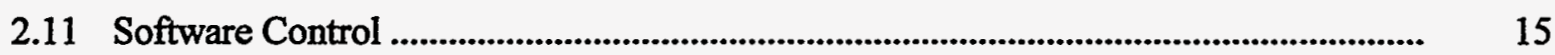

2.11.1 General Requirements .................................................................................. 15

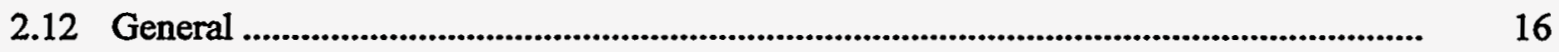

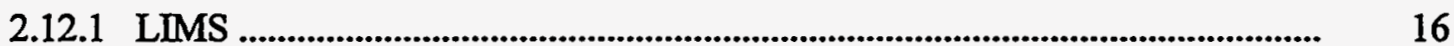

2.12.2 Conduct of Operations.............................................................................. 16

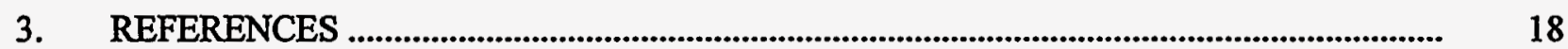

3.1 TWCP Related Documents........................................................................................ 18

3.2 LANL Analytical Chemistry Documents..................................................................... 18

3.3 LANL Miscellaneous Documents ............................................................................... 20

3.4 Other Documents........................................................................................................... 20

Appendix A-Lockheed Martin Idaho Technologies Company Environmental Restoration Program Quality Assessment Checklist.

Appendix B-Supplier Quality Assurance System Evaluation NQA-1 Basic Requirements 


\section{ACRONYMS}

ANC

ASME

CAO

CFR

CMR

$\mathrm{COC}$

DPESP

DOE

DOE-AL

DOE-ID

DP

EM

GALP

INEEL

LANL

LIMS

LMITCO

MOA

M\&TE

NMT

NQA

OJT

QA

QAPD

QAPP analytical (refers to analytical procedures)

American Society for Mechanical Engineers

Carlsbad Area Office

Code of Federal Regulations

Chemical and Metallurgy Research (Building)

chain-of-custody

Defense Program Environmental Surety Program

Department of Energy

Department of Energy Albuquerque Operations Office

Department of Energy Idaho Operations Office

Defense Programs

Environmental Management

good automated laboratory practices

Idaho National Engineering and Environmental Laboratory

Los Alamos National Laboratory

Laboratory Information Management System

Lockheed Martin Idaho Technologies Company

Memorandum of Agreement

material and test equipment

Nuclear Materials Technology

Nuclear Quality Assurance

on-the-job training

quality assurance

Quality Assurance Program Document

Quality Assurance Program Plan 
QAPjP Quality Assurance Project Plan

QC quality control

SOP Safe Operating Procedure

STTP Source-Term Waste Test Program

SQA software quality assurance

TRU Transuranic

TWCP Transuranic Waste Characterization Program 


\section{Quality Assurance Baseline Assessment Report For LANL Analytical Chemistry NMT-1 Operations}

\section{INTRODUCTION}

In FY-96, the Department of Energy (DOE) Defense Programs (DP) and the Idaho National Engineering and Environmental Laboratory (INEEL) Laboratory Director embarked on an innovative effort to integrate DOE Environmental Management (EM) skills with DOE-DP production skills and needs. The following policy statement was developed and used to form an agreement with the INEEL.

"Using a systems engineering approach, the INEEL will work with the existing weapons production designers to ensure environmentally sound techniques are used during each stage of the production life. INEEL will work cooperatively with the other Defense Program laboratories and sites to assure that all environmental laws are obeyed in the most cost-effective manner and the best engineering practices will be applied.”

This effort produced a Memorandum of Agreement (MOA) signed by the DOE Albuquerque (DOE-AL) and Idaho (DOE-ID) Operations Offices, that specifically, includes performance of facility assessments of various operations at Los Alamos National Laboratory (LANL).

One of the items tasked in the MOA was to perform a Quality Assurance (QA) Baseline Assessment of the newly organized Nuclear Material Technology (NMT) Analytical Chemistry Group (NMT-1).

After further discussion, with the NMT-1 management team, it was determined that the focus of the assessment should be on improvements needed to obtain certification to perform analyses of samples for the Transuranic Waste Characterization Program (TWCP). In light of this, the assessment team determined that the DOE Carlsbad Area Office (CAO) and TWCP QA documents, specifically the Quality Assurance Program Plan (QAPP) and the Quality Assurance Program Document (QAPD), would be used as a basis for the assessment. It was also noted that not all operations of NMT-1 would be applicable to the rigor of these requirements, but when possible the TWCP requirements would be considered using a graded approach. In cases where this was not practical, good laboratory practices were applied.

An assessment team was formed with a QA Engineer and four chemists with various backgrounds and laboratory experience. The team members were assigned Task Areas/analytical methods, to ensure that a complete overview of NMT-1 was performed. The details of the assessment process are in the "Implementation Work Plan for the Baseline Quality Assurance Assessment of the NMT-1 Analytical Chemistry Laboratory at LANL", INEEL/EXT-98-00740, August 1998.

The assessment was performed August 10-14, 1998. Checklists were used as an assessment tool (see Appendix A). 


\section{DISCUSSION}

Each of the NMT-1 Task Areas were evaluated according INEEL/EXT-98-00740, Implementation Work Plan for the Baseline Quality Assurance Assessment of the NMT-1 Analytical Chemistry Laboratory at LANL. This section includes general statements based upon specific observations (including procedure reference and Task Area) that are maintained in an INEEL DPESP file.

This section is formatted to correlate with relevant subsections of the DOE-CAO QAPD and QAPP, to facilitate referring to those documents for the specific requirements.

\subsection{Organization and Quality Assurance Program}

\subsubsection{Organization}

\section{Reference}

Both the QAPD (1.1.1) and QAPP (1.1) contain functional organization charts showing lines of authority and levels of communication.

\section{Observation}

The organization chart reviewed by the assessment team did not reflect the most current changes made in NMT-1.

\section{Recommendation}

Revise the organization chart to include the current changes made within NMT-1. It is understood that the group is still in transition to NMT Division, but special effort should be made to keep the organization chart up-to-date. The assessment team was given a copy of the NMT-1 Group Roster that contained titles of the work groups, under each Task Area. These work groups should be included in the functional organization chart. The production of this type of organizational chart should be included in QA-1 or in an implementation plan. This chart will also be useful for anyone needing information on the structure of NMT-1.

\subsubsection{Communication}

\section{Reference}

QAPD 1.1.1.6 discusses communication responsibilities. Communication channels shall be established "that provide timely, routine and wide dissemination of information pertinent to quality performance ..."

\section{Observation}

Currently, customer requirements are conveyed informally (e.g., phone calls, office visits, etc.), usually between the customer and a Task Area Leader. This system may provide adequate information for cost estimating and building profile lists, but the information is not documented appropriately or disseminated to all personnel. 


\section{Recommendations}

Customer requirements and other pertinent information should be clearly understood, agreed upon, and accessible to all personnel. These requirements should be documented and communicated through a formalized process.

A formalized means of documenting customer requirements should be established. The use of the Analytical Service Agreement could be extended to document these requirements. Another suggestion would be to revise and utilize the Analytical Chemistry Working Agreement or develop a generic Statement of Work document. This information should then be disseminated to each Task Area, as applicable.

\subsubsection{Interface Responsibilities}

\section{Reference}

QAPD 1.1.1.6 discusses interface responsibilities. When more than one organization (internal or external) is involved in executing activities, each organization's responsibility and authority shall be clearly established and documented.

\section{Observation}

It was not evident to assessment team members that a formalized system exists in which customer requirements and other requirements are communicated and documented within NMT-1. See comments in Section 2.1.2. Again, interface with others is performed in an informal manner.

\section{Recommendations}

Interface responsibilities may be established and documented through a procedure. These responsibilities can be easily combined with the communication responsibilities needed for Section 2.1.2. All customers and personnel interacting with NMT-1 should also review this procedure.

The formalized means of documenting customer requirements established (in Section 2.1.2) should be a required process for all customers to initiate and/or complete.

\subsubsection{QA Program Documents}

\section{Reference}

QAPD 1.1.2.1, states that "each program participant shall develop and follow procedures that effectively implement the requirements described herein ..."

\section{Observation}

The NMT-1 Quality Assurance Management Plan (QA-1) does not include the requirements for the TWCP, as written in the QAPD and QAPP. Also, this document contains references to the CST Division.

\section{Recommendations}

QA-1 must be rewritten to reflect the changes made in the organization structure. Changes should also be made to reflect the way that the QA program will be implemented in NMT-1. Areas (not all-inclusive) that should be incorporated or expounded upon are roles and responsibilities, 
delegation of work, dispute resolution, and graded approach. These items are discussed in the QAPD (Section 1, Management Requirements) and the QAPP (Section 1, Program Management). Refer to Table 1.1 of the $\mathrm{QAPP}$, which provides a cross-reference of $\mathrm{QA}$ requirements in relationship to the $\mathrm{QAPD}, 10$ CFR 830.120, and ASME NQA-1.

In order to perform work in support of the TWCP the QA requirements found in the DOE-CAO QA documents must be incorporated into an NMT-1 procedure. This could be performed by making additions to QA-1, or by writing a Quality Assurance Project Plan (QAPjP) or an implementation plan specifically for the TWCP.

Develop a procedure dictating the minimum QA requirements that all NMT-1 customers will receive. This procedure may include dictating minimum Quality Control (QC) requirements for analyses and data reporting criteria.

\subsubsection{Procedures Matrix}

\section{Reference}

QAPD 1.1.2.2 states that a procedures matrix shall be prepared and maintained that identifies all current and applicable documents.

\section{Observation}

In several cases, it was unclear to the assessment team which documents were applicable to this assessment. The procedures matrix found in LANL TRU Waste QA Management Plan (TWCP-PLAN-0.2.6-001, R.1) does not reflect the changes made in NMT-1.

\section{Recommendation}

The procedures matrix should be revised to incorporate all of the documents applicable to the TWCP. It is also suggested that a general document hierarchy chart (see QAPP Figure 1-2) be created that lists all documents applicable to NMT-1. It was noted that Quality and Planning Task Area personnel are working on revising the procedures matrix for the TWCP.

\subsubsection{Planning Work}

\section{Reference}

QAPD 1.1.2.5 states that "planning shall be performed and documented to ensure that work is accomplished under suitably controlled conditions." This planning process should be documented and should include scheduling and resource considerations.

\section{Observation}

There is not a formal system in place to ensure that analyses are completed on time, using appropriate methods (profiles), meeting all Quality Control (QC) requirements, and adhering to cost and schedule.

\section{Recommendations}

Formalize the work planning process through QA-1 or other procedure. 
Take a project management approach to individual projects by assigning one person or a team of people to handle customer requirements, scheduling, information dissemination, sample tracking, resource loading, etc. An example, the current use of an NMT-1 employee, located at TA-55, who is managing and coordinating, with CMR personnel, the analytical samples from the Plutonium Facility.

\subsection{Personnel Qualification and Training}

\subsubsection{Qualification and Training}

\section{Reference}

QAPD 1.2 discusses personnel qualification and training requirements. These requirements shall be established and documented. At a minimum, education, experience, and training (including on-the-job [OJT]) requirements should be identified.

\section{Observations}

After reviewing Table 1-4 of the QAPP (training and qualification requirements) it seemed evident that NMT-1 personnel should meet the qualifications required to perform work in support of the TWCP. OJT.

The Individual Training Plans that were reviewed only listed site-wide training and did not include

\section{Recommendations}

Qualification and training requirements should be documented in a procedure or other means. Personnel qualifications and training should be documented and placed in either personnel or training files.

Individual Training Plans should be revised to incorporate OJT requirements.

Develop lesson plans for OJT and proficiency training on analytical systems (equipment/profiles). These plans can then used as documentation of personnel qualification.

Conduct training on new and revised procedures, depending on the extent of the changes, instead of using required reading. Required reading has its place, but in the course of making major changes this is not be effective. This training should be delegated to a Task Area or Technical Leader.

\subsubsection{Special Training Requirements}

\section{Reference}

QAPP 1.6 states that before performing activities that affect program quality, all personnel are required to receive indoctrination regarding the scope, purpose, objectives, and specific QA objectives.

\section{Observation}

It was noted in several interviews of NMT-1 personnel that the purposes of the QA function and overall goals and objectives for the group were not known. 


\section{Recommendations}

Develop and present an indoctrination class to all NMT-1 personnel that discusses goals and objectives, general criteria, QA Plans, codes and regulation, implementing procedures and how these items correlate to the TWCP and other programs/projects supported by the group.

Actual training exercises on each revised QA document may also be useful.

\subsection{Quality Improvement}

\subsubsection{Nonconformance/Corrective Action}

\section{Reference}

QAPD 1.3, requires processes be established and implemented to detect and prevent conditions adverse to quality.

\section{Observation}

Several nonconformance issues were found throughout the laboratories. In many cases, these nonconformances were recognized by employees to exist, but the issues were not documented and corrective action put into place for resolution. In some cases personnel were unsure of the process to follow to correct these issues.

\section{Recommendation}

Review procedures to ensure that conformance information has been incorporated (e.g., tolerance limits for daily analytical balance checks). Review existing or write new procedures on managing nonconformance issues and performing corrective actions. Personnel should be trained on the appropriate use of these procedures.

\subsubsection{Operational Variance}

\section{Reference}

QAPP 2.1.2.2 addresses the issue of operational variances. It is understood that there will be situations in which "the need of a variance is caused by identification of improvements opportunities or unusual or nonroutine occurrences that affect operations but not the ability to achieve the performance standards or quality requirements."

\section{Observation}

Many of the nonconformance issues identified, by the INEEL team, had to do with equipment calibrations not being performed as scheduled. An example, many instances were observed of the annual calibration of an analytical balance being past due, while still being used to process samples. 


\section{Recommendation}

A program should be established that allows for operational variances. This program should include use of a Record of Variance form that could be approved by Task Area Leaders. This program would allow continuance of the activity for a specified time period. As in the example, continued use of the balance would be approved, contingent upon acceptable performance of daily calibration checks, until the annual calibration is performed.

\subsection{Documents}

\subsubsection{General Requirements}

Reference

QAPD 1.4.1 states that documents "shall be prepared, reviewed, approved, issued, used, and revised to prescribe processes, specify requirements, or establish design."

Observations.

There are two distinct document control processes in NMT-1. One system for normal routine operations and another, more rigorous, system for the Source-Term Waste Test Program (STTP).

QA-1 does not give enough detail pertaining to the document control process, i.e. actual tasks performed to establish and control documents, steps to initiate changes to documents, configuration management, etc.

Recommendations

A separate procedure should be written that specifically describes steps taken in all aspects of document control, including configuration management.

The document control system should integrate the current requirements for the STTP and use this program as a guideline for control of all NMT-1 documents.

See additional recommendations in sections 2.4 .2 and 2.4 .3 of this report.

\subsubsection{Document Review}

Reference

QAPD 1.4 states that documents "shall be reviewed for adequacy, correctness, and completeness."

\section{Observations}

Several of the procedures reviewed were not being followed as written.

Many of the procedures reviewed, contained references to the CST Division.

There were a few redundant procedures in place. 
It was noted that some personnel were working from a revised procedure that had not yet completed its review cycle.

Some procedures were found to be past the review due date.

\section{Recommendations}

All of the NMT-1 procedures should be reviewed, revised (as needed), trained to (as needed), and redistributed. It was noted that some of the procedures were well written and complete, but all of should be reviewed for content and implementation feasibility.

Redundant procedures should be consolidated.

The procedure review process should be evaluated and revised to ensure that documents are reviewed quickly and efficiently.

The adequacy of the tickler system for procedure reviews should be evaluated and revised to prevent the occurrence of past due document reviews.

\subsubsection{Document Distribution}

\section{Reference}

QAPD 1.4.2.2 discusses distribution and use of controlled documents. One of the requirements is that documents "shall be distributed to affected personnel and used at the work location."

QA-1 states that all "Analytical Chemistry personnel are responsible for maintaining a current procedure notebook or file of their printed documents."

\section{Observation}

It is unclear how readily accessible current copies of the procedures are to personnel. There is an on-line distribution system in which a current hard copy of a controlled procedure may be obtained, but hard copies were not observed in all of the work areas.

\section{Recommendations}

Procedures should be readily available to all personnel. A suggestion is to assign a document control person who creates binders containing hard copies of relevant procedures for each Task Area or work area. This would alleviate the need for each person to have a current procedure notebook or file. This person would then be responsible for keeping the information in these binders current.

Alternatively, an intranet web site could be created in which the procedures may be accessed and printed as needed. 


\subsection{Records}

\subsubsection{General Requirements}

\section{References}

QAPD 1.5.1 states that records "shall be specified, prepared, reviewed, approved, and maintained." records.

QAPD 1.5.2 discusses additional requirements such as generating, indexing and classifying

\section{Observation}

It was not clear whether all relevant documents have been identified as QA records. The list of documents in QA-1 should be reviewed for completeness.

\section{Recommendation}

QA and general records for NMT-1 need to be clearly defined. Defined records should be managed as dictated in subsequent steps of QAPD 1.5.2. Refer to Table 1.5 in the QAPP for list of QA records.

\subsubsection{Records Storage}

\section{Reference} facilities."

QAPD 1.5.2.6 states that " $\mathrm{QA}$ records shall be stored and preserved in predetermined storage

\section{Observation}

Potential QA and general records are being stored in individual offices, for indefinite periods of time. These documents are not being stored properly (i.e., in fire rated cabinets).

\section{Recommendation}

A centralized, easily accessible storage facility should be put into place.

\subsection{Work Processes}

\subsubsection{Work}

Reference

QAPD 2.1.1 discusses requirements for actual performance of tasks. Issues discussed include, but are not limited to the following: work shall be performed under controlled conditions using approved procedures; personnel performing work are responsible for the quality of their work. 


\section{Observations}

The technical excellence of the work that is being performed by NMT-1 personnel is not in question. Most observations revealed that the analyses (profiles) being performed are technically sound.

Procedures are not written to reflect the way tasks are actually performed.

\section{Recommendations}

Procedures should be reviewed for content and implementation feasibility. Procedures should be revised to read as the tasks are being performed or personnel should be required to follow the procedures as written. The importance of procedure compliance should be clearly communicated to personnel.

Conduct training on new and revised procedures, depending on the extent of the changes, instead of using required reading. Required reading has its place, but in the course of making major changes this may not be effective. This should be delegated to the Task Area or Technical Leader.

Expand administrative and technician staff to perform tasks, that are less technical in nature, such as data compilation/gathering, data entry (in spreadsheets and in the Laboratory Information Management System [LIMS]), data packaging, and data/sample tracking.

\subsubsection{Acceptable Work Performance}

\section{Reference}

QAPD 2.1.1 establishes management involvement in the work processes through interactions with personnel and through review and verification of ongoing and completed work. Acceptable work performance must be clearly communicated and personnel must have the necessary training and resources to accomplish their tasks.

\section{Observation}

Generally, it is unclear as to how resource loading, work control, and overall of tracking of work is performed.

\section{Recommendations}

A formalized system should be put into place to plan and track the work that is being performed.

Resource loading issues should be addressed in order to determine whether adequate resources are available to perform work for the TWCP or any additional projects.

\subsection{Inspection and Testing}

\subsubsection{Use and Control of Measuring and Test Equipment (M\&TE)}

Reference

QAPD 2.4.3.1 states, "establish and document a system to control the use and calibration of M\&TE." A program should be in place "to recall for calibration, or remove from service, M\&TE that has exceeded its calibration interval." 


\section{Observation}

There were several instances of equipment (e.g., analytical balances, pipettes, and thermometer) past the calibration due date and still in use. It was noted through discussions that the calibration program issue is a site-wide problem.

\section{Recommendations}

Despite the site-wide issue, M\&TE should be placed out-of-service until recalibrated.

A program should be established that allows for operational variances. This program should include use of a Record of Variance form that could be approved by Task Area Leaders. This would then allow continuance of the activity for a specified time period.

Form a qualified NMT-1 calibration team. There are many pieces of equipment in NMT-1 that need consistent calibration. In light of the "site-wide" issues, this may be an option.

\subsubsection{Calibration of M\&TE}

\section{References} followed.

QAPD 2.4.3.1 requires that records documenting that M\&TE schedules and procedures have been

QAPD 2.4.3.2 states that M\&TE requiring calibration is done so at specified intervals.

\section{Observation}

There is a system, in place, to track items in need of calibration, which also has the ability to track all other routine, dated activities. This system is currently not being used by all Task Areas.

Unfortunately, this tracking system does not preclude the problems associated with actual performance of the required calibration activities.

\section{Recommendations}

Frequency of calibration should be clearly defined and known by personnel (i.e., calibration of pipettes). These frequencies should be written in procedures.

The current tracking system should be reviewed and expanded for use by all Task Areas.

\subsection{Assessment and Oversight}

\subsubsection{Management Assessments}

\section{Reference}

QAPD 3.1 states "managers at every level shall periodically assess the performance of their organization ... This assessment shall place emphasis on the use of human and material resources to achieve organizational goals and objectives." These assessments shall be conducted regularly and reported at least annually. 


\section{Observation}

No documentation was observed to support the performance of periodic management assessments.

\section{Recommendation}

-Management assessments should be performed periodically. This task may be delegated to staff members, but it is the sole responsibility of management personnel to ensure that they are being completed. These assessments should be documented and contents distributed to personnel for review. It is also suggested that a schedule (including areas to be assessed) be posted for personnel information.

\subsubsection{Independent Assessments}

\section{Reference}

QAPD 3.2 states "planned and periodic independent assessments shall be conducted to measure item and service quality, process effectiveness, and to promote improvement." A program of surveillances and audits shall be planned, performed, documented, and reported to management personnel.

\section{Observation}

Periodic independent assessments are being performed by personnel external to NMT-1, but not by personnel internal to NMT-1.

\section{Recommendations}

Independent assessments should be performed periodically. QA personnel may perform this task, since they do not perform actual chemical analyses. The purpose of these assessments should be to ensure compliance with the QA program and procedures. These assessments should be documented and contents distributed to personnel for review. It is also suggested that a schedule (including areas to be assessed) be posted for personnel information.

In light of the reorganization and potential changes in the type of samples to be worked at NMT-1, higher visibility and management recognition of the QA staff is very important.

\subsection{Sample Management}

\subsubsection{Sample Control}

\section{Reference}

QAPD 4.1 requires that provisions be made for the "identification, handling, storage and shipping, archival, and disposition of the samples."

\section{Observation}

The sample management process is viewed as the hub of any analytical chemistry laboratory. There were several inconsistencies noted in NMT-1's sample management process (e.g., sample receipt and sample log-in) and it was not always clear as to how certain tasks (e.g., building profile templates) are performed. 


\section{Recommendations}

Review and revise current Sample Management procedures to reflect the way samples are actually being managed in NMT-1.

All NMT-1 personnel should understand and be trained to the sample management process. Each person should understand how his or her specific task fits into the overall process.

\subsubsection{Sample Possession/Chain-of-Custody (COC)}

Reference

QAPD 4.1 requires that "implementing procedures shall define responsibilities, including organizational interfaces, related to documenting and tracking sample possession ..." at all stages of sample handling.

Observations

Currently, most of the samples received in the group do not require formal COC because it is not dictated by the projects being worked. It was not clear as to how samples are tracked within the Sample Management Task Area.

Currently, the individual Task Areas track samples in the work areas, using spreadsheets (i.e., Excel), which reside on individual personal computers.

Recommendations

A minimum level of tracking and custody should be established for the group.

The COC procedure should be reviewed and revised to handle various levels of rigor in receiving and distributing of samples.

The use of spreadsheets for tracking samples may be an acceptable practice, but the information should be incorporated into LIMS to enhance the overall use of the LIMS.

\subsubsection{Disposition of Samples}

Waste management was outside of the scope of this assessment and therefore not evaluated.

\subsection{Data Management}

\subsubsection{Data Recording}

\section{Reference}

QAPD 5.3.1 states "the method of data recording (e.g., scientific notebooks, log books, data sheets, or computerized instrumentation systems) shall be controlled to avoid data loss and permit data retrievability." 


\section{Observations}

The technical capabilities of NMT-1 personnel are not at question, but what is of concern is the ability to generate reproducible and defensible data (refer to SW-846, Chapter One), through proper management of that data.

Some data is not being recorded properly, i.e. in indelible ink, recorded daily, etc.

Results are not always entered into the LIMS.

There were several instances in which the use of logbooks did not follow the NMT-1 procedure on logbooks and notebooks.

\section{Recommendations}

A procedure should be written that governs method of recording data, including requirements for entering data into the LIMS.

Obtain list of all logbooks, currently in use and review for content. Determine if they comply with procedure and if they are actually needed.

Create pre-printed logbook pages that could be bound, to ensure that necessary and relevant information is being recorded. This is especially helpful for maintenance and calibration logbooks.

\subsubsection{Data Transfer and Reduction}

\section{Reference}

QAPD 5.3.1 states "controls shall be established to ensure that data transfer is error free (or within a prescribed permissible error rate); that no information is lost in transfer; and that the input is completely recoverable."

\section{Observation}

There are several spreadsheets that are being used, in various Task Areas, in which the data is being calculated and reduced then downloaded directly into the LIMS.

\section{Recommendations}

A procedure should be written that formalizes the process of data transfer and reduction.

Good examples of the spreadsheets should be evaluated for use throughout the group.

Use examples, from various Task Areas, of spreadsheets that currently download data automatically to the LIMS.

\subsubsection{Data Collection, Analysis, and Reporting}

\section{Reference}

QAPD 5.3.1 states "data collection and analysis shall be critically reviewed and questions resolved before results are either used or reported." 


\section{Observation}

Results are not always entered into the LIMS for reporting and final approval. There were instances in which data (results) were reported verbally to a customer without further documentation.

\section{Recommendations}

A procedure should be written that formalizes the process of data collection, analysis, and reporting.

All data should be documented and reviewed (including logbooks) before being reported.

Report generation activities (including data packaging, where applicable) should be evaluated to establish a more efficient process. Currently, this job is very cumbersome in some Task Areas.

\subsubsection{Data Validation}

\section{Reference}

QAPP 3.2 requires that "validation of all data (qualitative as well as quantitative) shall be performed so that data used for WIPP compliance programs will be of known and acceptable quality."

\section{Observation}

Documentation of method performance was not always evident. Control charts were produced at various frequencies and in some cases, not at all.

\section{Recommendation}

Procedures should be reviewed to ensure there is a process of documenting method performance. This may include periodic precision and accuracy evaluations and control chart production. The frequency of performing these tasks should be clearly defined.

\subsection{Software Control}

\subsubsection{General Requirements}

\section{Reference}

QAPD 6.1 discusses software quality assurance (SQA) requirements, including inventory, classification, verification, validation, configuration management, and documentation of software.

\section{Observations}

Many spreadsheets (non-commercial software) are being used throughout the group, to track, manipulate, calculate, and report data. There is no evidence that these spreadsheets have been inventoried, validated, verified, and approved for use. There has been an attempt, in one of the Task Areas, to begin the validation/verification process.

It was also noted that many of the spreadsheets, used in various Task Areas, are very effective. 


\section{Recommendations}

The process of maintaining SQA should be written in a procedure, specifically for the use of spreadsheets. All information should be documented.

As a means to increase the efficiency, in certain Task Areas, the effective spreadsheets from other Task Areas should be modeled.

Obtain a list of all spreadsheets. All of these spreadsheets will need to be tracked, controlled, validated, verified, and approved.

A separate INEEL team will perform a more in depth software quality assurance (SQA) assessment.

\subsection{General}

\subsubsection{LIMS}

References

Environmental Protection Agency (EPA) Good Automated Laboratory Practices, 1990.

EPA Good Automated Laboratory Practices Implementation Assistance, 1995.

\section{Observations}

The LIMS is not being used to its fullest capabilities. Personnel seem reluctant to enter data, utilize tracking functions, utilize potential data calculation and manipulation functions, etc.

There were several instances of inconsistent sample log-in and data entry into the LIMS.

\section{Recommendations}

LIMS is a tool that should be used and modified, if applicable, to enhance work processes and increase overall efficiencies of NMT-1 operations.

Management should continue to stress the importance and set requirements for the use of the LIMS. Requirements and use of the LIMS should be written in a procedure. The EPA GALP document is a good source of information for LIMS.

\subsubsection{Conduct of Operations}

Reference

DOE Order 5480.19, Conduct of Operations.

\section{Observation}

Several Conduct-of-Operations concerns were raised during this assessment. One example is the use of operator aids in the laboratories. An example, an operator aid on a sample preparation procedure, posted in the work area, deviated from the actual analytical (ANC) procedure. 


\section{Recommendations}

Operator aids, in many cases, are essential to increasing the efficiency of work process, but these aids should be documented and controlled, to ensure controlled procedures are not being violated.

The area of Conduct of Operations was out of the scope of this assessment, but should be reviewed for NMT-1 operations. 


\section{REFERENCES}

\subsection{TWCP Related Documents}

DOE-CAO, "DOE-CAO, Transuranic Waste Characterization Quality Assurance Program Plan,"

CAO-94-1010, Rev. 0.

DOE-CAO, “Quality Assurance Program Document,” CAO-94-1012, Rev. 1.

LANL, "Los Alamos National Laboratory Transuranic Waste Quality Assurance Management Plan," TWCP-PLAN-0.2.3-001, Rev. 1.

LANL, "Los Alamos National Laboratory Transuranic Waste Characterization Quality Assurance Project Plan," TWCP-PLAN-0.2.6-001, Rev. 1.

\subsection{LANL Analytical Chemistry Documents}

LANL, "Transuranic Waste - Microwave Assisted Sample Preparation," ANC-100, Rev. 1.

LANL, "Cold Vapor Atomic Fluorescence Spectroscopy Using the PS Analytical CVAF HG Analyze," ANC-101, Rev. 1.

LANL, "ESCAVAuger Spectroscopic Examination of Solids," ANC-104, Rev. 2.

LANL, "U \& Pu Isotopic Distribution and Assay by Isotopic Dilution Mass Spectrometry,"ANC-131, Rev. 2.

LANL, “Trace element Analysis - Open Hot-Plate Acid Digestion,” ANC-132, Rev. 1.

LANL, “Analysis of Gas Mixtures by Mass Spectrometry,” ANC-136, Rev. 1.

LANL, "Metallographic Sample Preparation," ANC-137, Rev. 0.

LANL, "Dry Ashing of Analytical Samples," ANC-139, Rev. 0.

LANL, "Trace-Element Analysis - Microwave-Assisted Sample Preparation," ANC-142, Rev. 0.

LANL, "X-Ray Fluorescence Analysis of High Purity Metals and Alloys," ANC-186, Rev. 2.

LANL, "Inductively Coupled Plasma - Atomic Emission Spectroscopy Using the Thermo Jarrell Ash IRIS Spectrometer," ANC-189, Rev. 0.

LANL, " Plutonium-238 Sample Analysis," ANC-300, Rev. 0.

LANL, "Plutonium by 2 - Thenoyltrifluoroacetone (TTA) Extraction - Radiochemical Determination," ANC-301, Rev. 0.

LANL, "Operational Checks of Automatic Alpha and Gamma Counters," ANC-302, Rev. 3.

LANL, "Operational Check of the Automatic Liquid Scintillation Counter," ANC-303, Rev. 0. 
LANL, "Operational Check of the Alpha Spectroscopy System," ANC-304, Rev. 2.

LANL, "Plutonium and Americium-241 - Radioanalytical Determination," ANC-305, Rev. 0.

LANL, "Preparation of Radiochemistry Instrument Calibration Standards," ANC-306, Rev. 0.

LANL, "Preparing Calibration Reference Materials for NMT Division Assay Instruments," ANC-326, Rev. 0.

LANL, Total Uranium and ${ }^{235} U /^{238} U$ in Water or Soil Extracts - ICPMS," ANC-336, Rev. 1.

LANL, "Uranium in environmental Matrices - KPA," ANC-337, Rev. 0.

LANL, "Alpha Autoradiography at the Chemistry and Metallurgy Research (CMR) Building," ANC-348, Rev. 0.

LANL, "Plutonium Isotopic Analysis by Gamma-Ray Spectroscopy," ANC-366, Rev. 0.

LANL, "Semivolatile Organics in Solid Matrices - Solvent Extraction," ANC-609, Rev. 0.

LANL, "Semivolatile Organics - GCMS," ANC-611, Rev. 1.

LANL, "Organic Compounds - Standards Preparation," ANC-612, Rev. 1.

LANL, "TRU Waste Characterization Program - Semivolatile Extraction and Analysis," ANC 613, Rev. 0.

LANL, "Total Nonhalogenated Volatile Organic Compounds - GCFID," ANC-629, Rev. 0.

LANL, "Volatile Organic Compounds in Radioactive and Non-radioactive Matrices," ANC-632, Rev. 0.

LANL, "Receiving and Unpackaging of Sample Shipments," ANC-900, Rev. 0.

LANL, "Transferring of Nuclear Material Samples in/out of Inert Atmosphere Glovebox Systems in Sample Management," ANC-901, Rev. 1.

LANL, "Regeneration of Sample Management Inert Atmosphere Gloveboxes," ANC-902, Rev. 0.

LANL, "Sample Management," ANC-904, Rev. 1.

LANL, "Chain of Custody," ANC-909, Rev. 0.

LANL, "Storing Samples in Analytical Chemistry," ANC-911, Rev. 1.

LANL, "Analytical Sample Receipt, Subsampling, and Distribution within the CMR," ANC-914, Rev, 0.

LANL, "Analytical Chemistry Quality Management Plan," QA-1, Rev. 1.

LANL, "Procedure Content and Format Guide," QA-2. Rev. 0.

LANL, "Developing Procedures, Plans, and Instructions for Inspecting and Acceptance Criteria," QA-3, Rev. 0. 
LANL, "Nonconformance Reporting," QA-8, Rev. 0.

LANL, "Maintaining Notebooks and Logbooks," QA-9, Rev. 0.

LANL, "Analytical Chemistry Statistics - Determination and Handling of Outliers," QA-17, Rev. 0.

LANL, "Analytical Chemistry Method Validation," QA-18, Rev. 0.

LANL, "Control of Operator Aids for CST-1," QA-20, Rev. 0.

LANL, "Calibration of Weights and Balances," QC-2, Rev. 5.

LANL, "Good Laboratory Practices for Analytical Chemistry," QC-13, Rev. 0.

LANL, "Control and Documentation of Analytical Chemical Standards," QC-15, Rev. 0.

LANL, "Analytical Balance Verification," QC-17, Rev. 0.

LANL, "Monitoring Laboratory Water Quality," QC-18, Rev. 0.

LANL, "Wavelength Dispersive and Energy Dispersive X-Ray Fluorescence," SOP-12, Rev. 3.

LANL, "X-Ray Generator Providing an Enclosed X-Ray Beam for Laue Reflection and Powder Diffraction Equipment," SOP-15, Rev. 1.

\subsection{LANL Miscellaneous Documents}

LANL, "Los Alamos National Laboratory Quality Management Plan," PRD-110-01.0

LANL, "Los Alamos National Laboratory TA-55 Plutonium Facility Quality Management Plan," TA-55-PRD-110-01.2,

\subsection{Other Documents}

U. S. DOE, "Conduct of Operations Requirements for DOE Facilities," DOE Order 5480.19, July 9, 1990.

U.S. EPA, "Environmental Protection Agency (EPA) Good Automated Laboratory Practices," Draft, December 28, 1990.

U.S. EPA, “EPA Good Laboratory Practices Implementation Assistance,” 2185, 1995 Ed., August 10, 1995.

U.S. EPA, “Test Methods for Evaluating Solid Waste, Physical/Chemical Methods," SW-846, June 13, 1997. 


\section{Appendix A}

Lockheed Martin Idaho Technologies Company Environmental Restoration Program Quality Assessment Checklist 

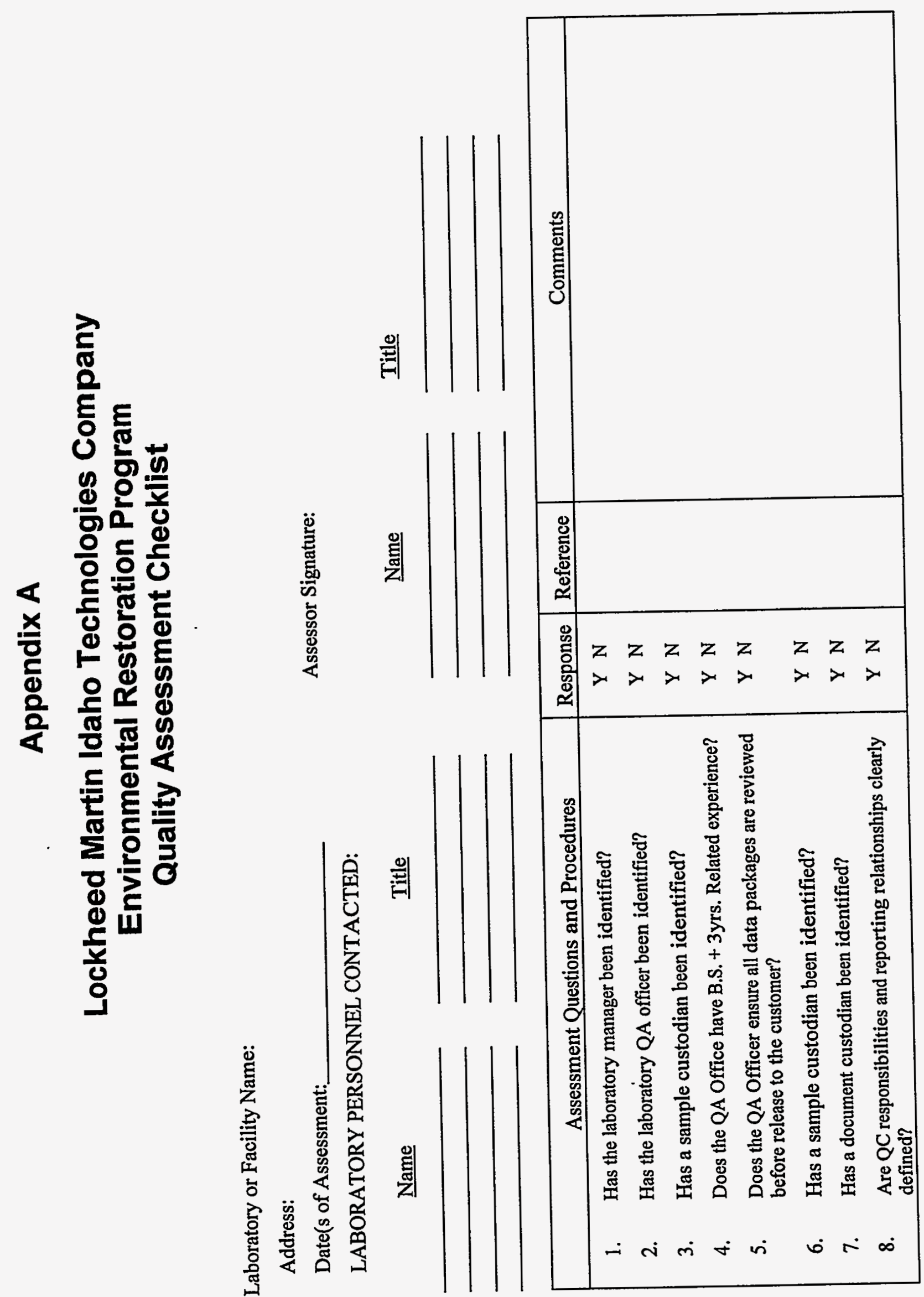


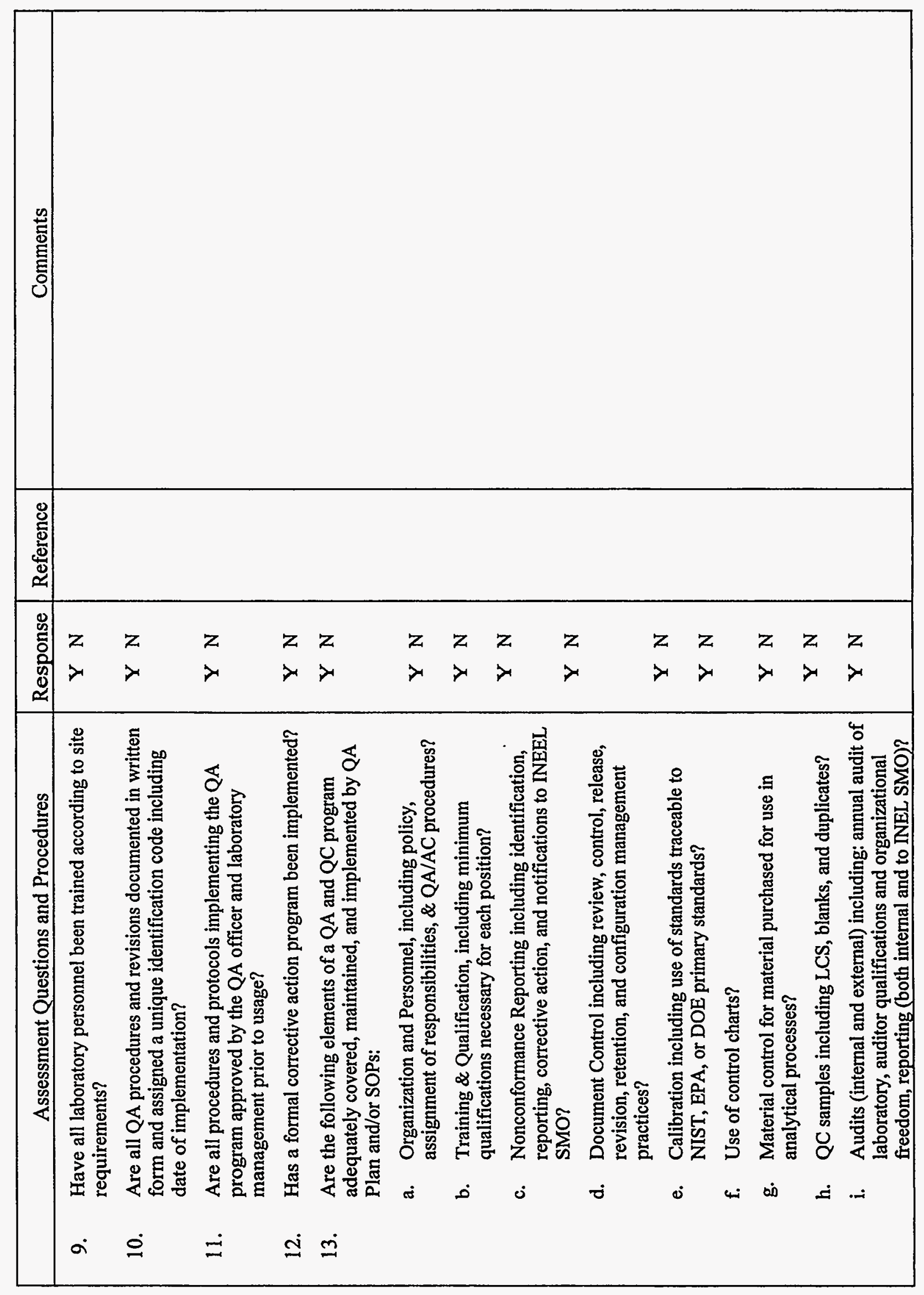




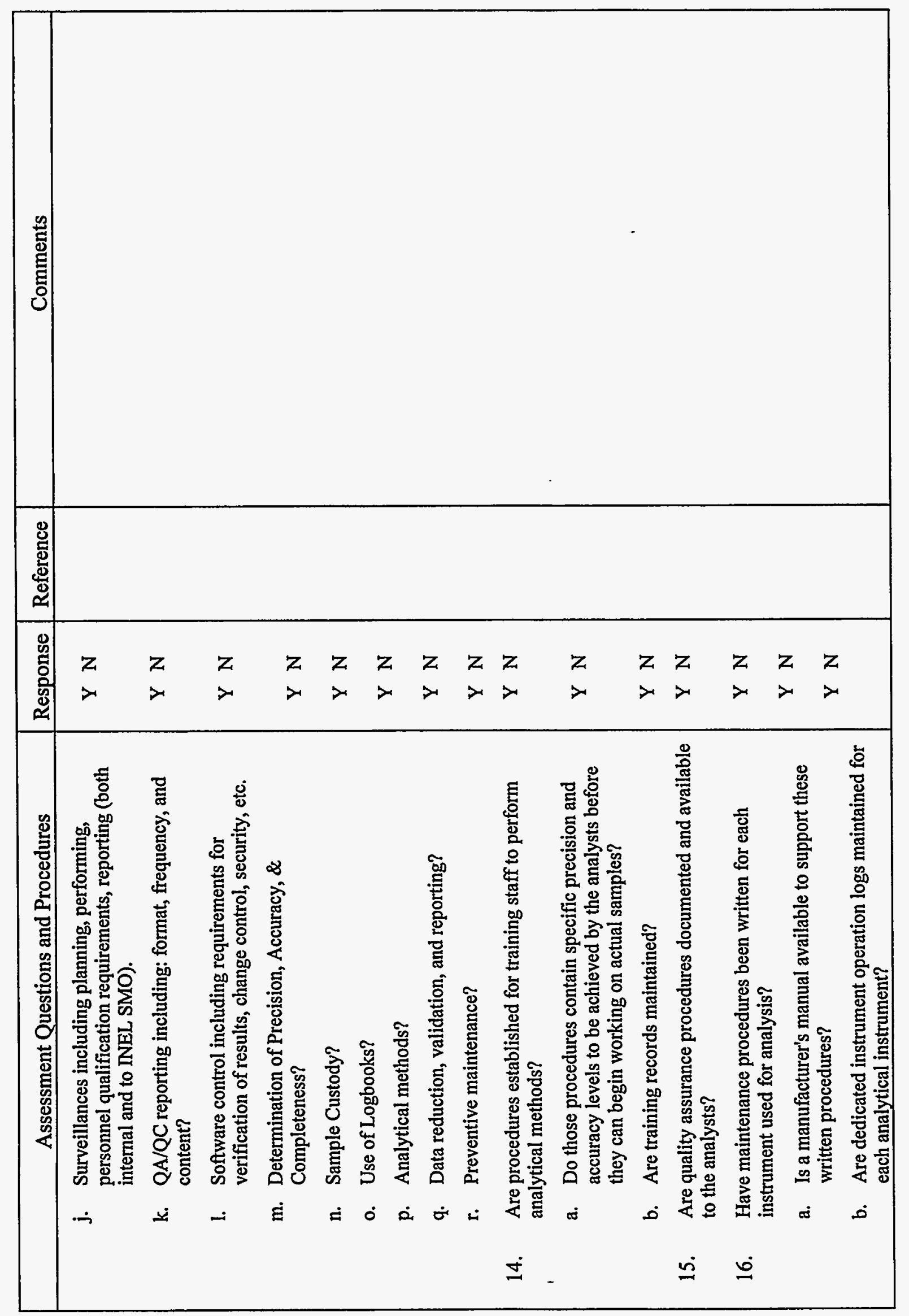




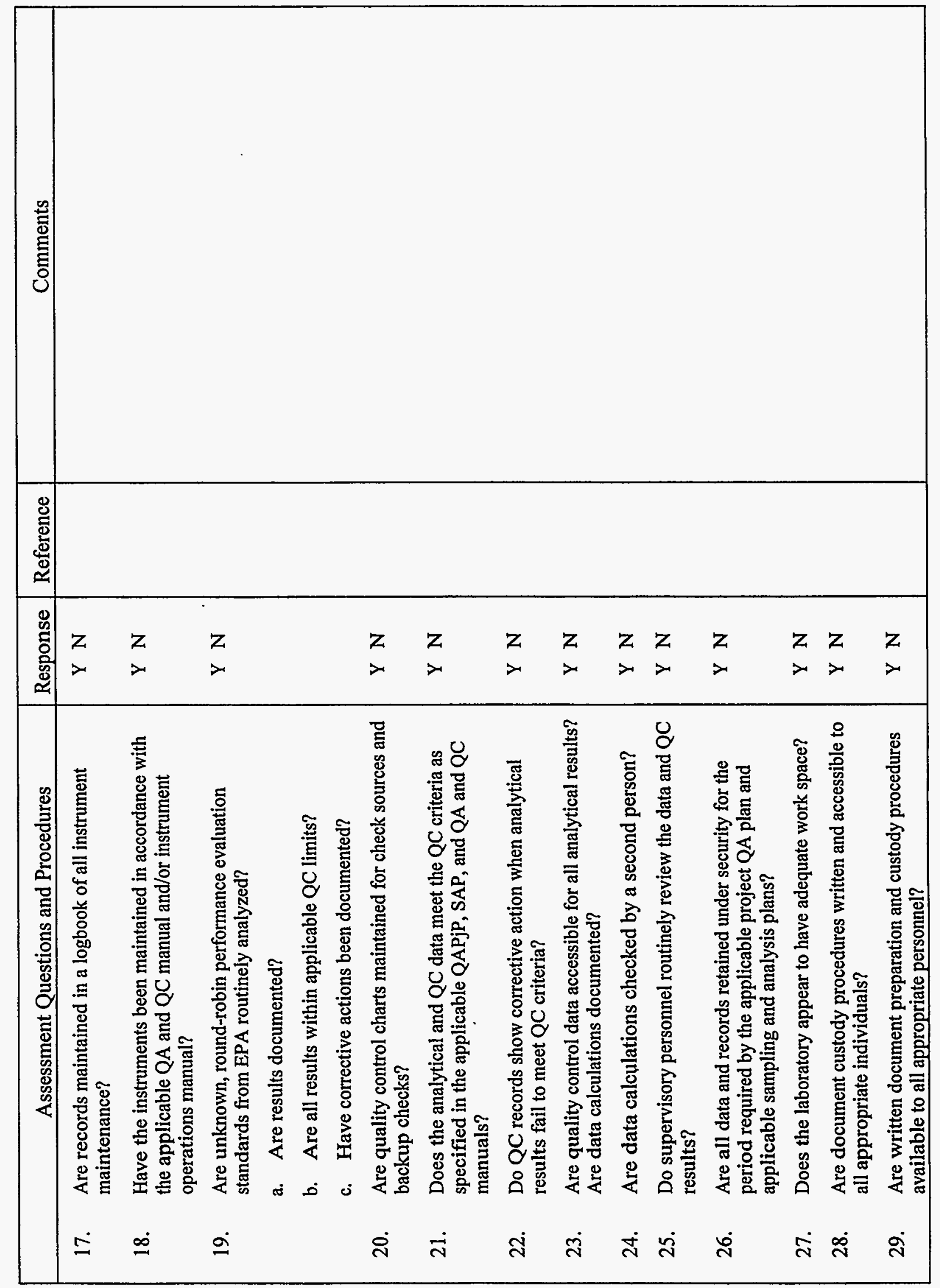




$$
\square
$$


Appendix B

Supplier Quality Assurance System Evaluation NQA-1 Basic Requirements 


\section{Appendix B}

\section{Supplier Quality Assurance System Evaluation NQA-1 Basic Requirements}

\begin{tabular}{|c|c|c|c|c|c|c|c|}
\hline & \multicolumn{3}{|r|}{ NQA-1 Basic Requirements Checklist } & Ref. & Yes & No & Notes \\
\hline \multirow[t]{8}{*}{1.0} & \multicolumn{3}{|c|}{ Organization } & & & & \\
\hline & 1.1 & \multicolumn{2}{|c|}{$\begin{array}{l}\text { Is the supplier's organizational structure, functional } \\
\text { responsibilities, and levels of communication for } \\
\text { activities affecting quality documented? }\end{array}$} & BR-1 & & & \\
\hline & 1.2 & \multicolumn{2}{|c|}{$\begin{array}{l}\text { Does the supplier's program specify that persons or } \\
\text { organizations responsible for assuring that an appropriate } \\
\text { quality assurance program has been established, and for } \\
\text { verifying that activities affecting quality have been correctly } \\
\text { performed, have sufficient authority to access work areas, } \\
\text { and organizational freedom to: }\end{array}$} & BR-1 & & & \\
\hline & & 1.2 .1 & identify quality problems; & & & & \\
\hline & & 1.2 .2 & $\begin{array}{l}\text { initiate, recommend, or provide solutions to } \\
\text { quality programs through designated channels; }\end{array}$ & & & & \\
\hline & & 1.2 .3 & verify implementation of solutions; & & & & \\
\hline & & 1.2 .4 & $\begin{array}{l}\text { assure that further processing, delivery } \\
\text { installation, or use, is controlled until proper } \\
\text { disposition of a nonconformance or deficiency, } \\
\text { has occurred? }\end{array}$ & & & & \\
\hline & 1.3 & $\begin{array}{l}\text { Do su } \\
\text { indept }\end{array}$ & $\begin{array}{l}\text { persons or organizations have sufficient } \\
\text { lence from cost and schedule considerations? }\end{array}$ & BR-1 & & & \\
\hline \multirow[t]{9}{*}{2.0} & \multicolumn{3}{|c|}{ Quality Assurance Program } & & & & \\
\hline & 2.1 & \multicolumn{2}{|c|}{$\begin{array}{l}\text { Has a documented quality assurance program been planned, } \\
\text { implemented, and maintained in accordance with NQA-1 or } \\
\text { equivalent? }\end{array}$} & BR-2 & & & \\
\hline & 2.3 & \multicolumn{2}{|c|}{$\begin{array}{l}\text { Does the program take into consideration the technical } \\
\text { aspects of the activities affecting quality? }\end{array}$} & BR-2 & & & \\
\hline & 2.4 & \multicolumn{2}{|c|}{$\begin{array}{l}\text { Does the program provide control over activities affecting } \\
\text { quality to an extent consistent with their importance? }\end{array}$} & BR-2 & & & \\
\hline & 2.6 & \multicolumn{2}{|c|}{$\begin{array}{l}\text { Does the program provide for the planning and execution of } \\
\text { activities affecting quality under controlled conditions? }\end{array}$} & BR-2 & & & \\
\hline & & 2.6 .1 & using appropriate equipment, & & & & \\
\hline & & 2.6 .2 & $\begin{array}{l}\text { providing suitable environmental conditions for } \\
\text { the activity, and }\end{array}$ & & & & \\
\hline & & 2.6 .3 & $\begin{array}{l}\text { providing assurance that prerequisites for the } \\
\text { activity have been satisfied? }\end{array}$ & & & & \\
\hline & 2.7 & \multicolumn{2}{|c|}{$\begin{array}{l}\text { Does the program provide for special processes, test } \\
\text { equipment, tools, and skills to achieve quality } \\
\text { requirements? }\end{array}$} & BR-2 & & & \\
\hline
\end{tabular}




\begin{tabular}{|c|c|c|c|c|c|c|c|}
\hline & \multicolumn{3}{|r|}{ NQA-1 Basic Requirements Checklist } & Ref. & Yes & No & Notes \\
\hline & 2.8 & \multicolumn{2}{|c|}{$\begin{array}{l}\text { Does the program provide for quality verifications, such as } \\
\text { inspections, tests, audits, surveillances, and reviews? }\end{array}$} & BR-2 & & & \\
\hline & 2.9 & \multicolumn{2}{|c|}{$\begin{array}{l}\text { Does the program provide indoctrination and training of } \\
\text { personnel performing activities affecting quality and assure } \\
\text { that proficiency levels are maintained? }\end{array}$} & BR-2 & & & \\
\hline & 2.10 & \multicolumn{2}{|c|}{$\begin{array}{l}\text { Does management of the organizations implementing the } \\
\text { quality assurance program, regularly assess the adequacy of } \\
\text { the program and assure its effective implementation? }\end{array}$} & BR-2 & & & \\
\hline \multirow[t]{8}{*}{3.0} & \multicolumn{3}{|c|}{ Design Control } & & & & \\
\hline & \multirow[t]{6}{*}{3.1} & \multicolumn{2}{|c|}{ Does the supplier's program require that: } & & & & \\
\hline & & 3.1 .1 & designs be defined, controlled, and verified, & BR-3 & & & \\
\hline & & 3.1 .2 & $\begin{array}{l}\text { applicable design inputs be appropriately } \\
\text { specified on a timely basis, and translated into } \\
\text { design documents, }\end{array}$ & BR-3 & & & \\
\hline & & 3.1.3 & design interfaces be identified and controlled, & BR-3 & & & \\
\hline & & 3.1 .4 & $\begin{array}{l}\text { design adequacy be verified by persons other than } \\
\text { those who designed the item, }\end{array}$ & BR-3 & & & \\
\hline & & 3.1 .5 & $\begin{array}{l}\text { design changes, including field changes be } \\
\text { governed by control measures commensurate with } \\
\text { those applied to the original design? }\end{array}$ & BR-3 & & & \\
\hline & 3.2 & \multicolumn{2}{|c|}{$\begin{array}{l}\text { Do the responsible design organizations identify, document } \\
\text { review, and approve applicable design inputs, such as } \\
\text { design bases, performance requirements, regulatory } \\
\text { requirements, codes, and standards? }\end{array}$} & BR-3 & & & \\
\hline \multirow[t]{2}{*}{4.0} & \multicolumn{3}{|c|}{ Procurement Document Control } & & & & \\
\hline & 4.1 & \multicolumn{2}{|c|}{$\begin{array}{l}\text { Are applicable design bases and other requirements } \\
\text { necessary to assure adequate quality, included or referenced } \\
\text { in procurement documents? }\end{array}$} & $\mathrm{BR}-4$ & & & \\
\hline \multirow[t]{3}{*}{5.0} & \multicolumn{3}{|c|}{ Instructions, Procedures, and Drawings } & & & & \\
\hline & 5.1 & \multicolumn{2}{|c|}{$\begin{array}{l}\text { Are the activities affecting quality prescribed by, and } \\
\text { performed in accordance with documented instructions, } \\
\text { procedures, and drawings? }\end{array}$} & BR-5 & & & \\
\hline & 5.2 & \multicolumn{2}{|c|}{$\begin{array}{l}\text { Do such documents include, or reference appropriate } \\
\text { quantitative and qualitative acceptance criteria for } \\
\text { determining that prescribed activities are accomplished? }\end{array}$} & BR-5 & & & \\
\hline \multirow[t]{3}{*}{6.0} & \multicolumn{3}{|c|}{ Document Control } & & & & \\
\hline & 6.1 & \multicolumn{2}{|c|}{$\begin{array}{l}\text { Does the supplier's program provide for the control of } \\
\text { documents that specify quality requirements, or prescribe } \\
\text { activities affecting quality, to assure that correct documents } \\
\text { are being utilized? }\end{array}$} & BR-6 & & & \\
\hline & & 6.1 .1 & $\begin{array}{l}\text { Are such documents, including revisions, } \\
\text { reviewed for adequacy and approved by } \\
\text { authorized personnel? }\end{array}$ & & & & \\
\hline
\end{tabular}




\begin{tabular}{|c|c|c|c|c|c|c|}
\hline \multicolumn{3}{|r|}{ NQA-1 Basic Requirements Checklist } & Ref. & Yes & No & Notes \\
\hline \multirow[t]{6}{*}{7.0} & Contr & ol of Purchased Items and Services & \multirow{6}{*}{ BR-7 } & & & \\
\hline & 7.1 & $\begin{array}{l}\text { Is the procurement of items and services controlled to } \\
\text { assure conformance with specified requirements, and do the } \\
\text { controls provide for: }\end{array}$ & & & & \\
\hline & & 7.1.1 source evaluation and selection, & & & & \\
\hline & & $\begin{array}{l}\text { 7.1.2 evaluation of objective evidence of quality } \\
\text { furnished by the supplier, }\end{array}$ & & & & \\
\hline & & 7.1.3 source inspection, audit, and & & & & \\
\hline & & $\begin{array}{l}\text { 7.1.4 examination of items and services upon delivery } \\
\text { or completion? }\end{array}$ & & & & \\
\hline \multirow[t]{3}{*}{8.0} & \multicolumn{3}{|c|}{ Identification and Control of Items } & & & \\
\hline & 8.1 & $\begin{array}{l}\text { Are identification and control measures established to } \\
\text { assure that only correct and accepted items are } \\
\text { utilized? }\end{array}$ & BR-8 & & & \\
\hline & 8.2 & $\begin{array}{l}\text { Has identification been maintained either on the items or in } \\
\text { documents traceable to the items? }\end{array}$ & BR-8 & & & \\
\hline \multirow[t]{3}{*}{9.0} & \multicolumn{2}{|c|}{ Control of Processes } & & & & \\
\hline & 9.1 & $\begin{array}{l}\text { Are the processes that affect the quality of items or services } \\
\text { controlled? }\end{array}$ & BR-9 & & & \\
\hline & 9.2 & $\begin{array}{l}\text { Are the special processes that control or verify quality, such } \\
\text { as those used in welding, heat treating, and nondestructive } \\
\text { examination, performed by qualified personnel using } \\
\text { qualified procedures? }\end{array}$ & BR-9 & & & \\
\hline \multirow[t]{5}{*}{10.0} & \multicolumn{2}{|c|}{ Inspection } & & & & \\
\hline & 10.1 & $\begin{array}{l}\text { Are inspections that verify conformance BR-1 to } \\
\text { requirements planned and executed? }\end{array}$ & BR-10 & & & \\
\hline & 10.2 & $\begin{array}{l}\text { Are the characteristics to be inspected, and the } \\
\text { inspection methods employed specified? }\end{array}$ & BR-10 & & & \\
\hline & 10.3 & Are the inspection results documented? & BR-10 & & & \\
\hline & 10.4 & $\begin{array}{l}\text { Have the inspections for acceptance been performed by } \\
\text { persons other than those who performed or directly } \\
\text { supervised the work being inspected? }\end{array}$ & BR-10 & & & \\
\hline \multirow[t]{4}{*}{11.0} & \multicolumn{2}{|c|}{ Test Control } & & & & \\
\hline & 11.1 & $\begin{array}{l}\text { Are test control measures that verify conformance of an } \\
\text { item to specified requirements, and demonstrate that items } \\
\text { will perform satisfactorily, planned, reviewed, and } \\
\text { implemented? }\end{array}$ & BR-11 & & & \\
\hline & 11.2 & $\begin{array}{l}\text { Are the characteristics to be tested and test methods to be } \\
\text { utilized, specified? }\end{array}$ & BR-11 & & & \\
\hline & 11.3 & $\begin{array}{l}\text { Are test results documented, and their conformance with } \\
\text { acceptance criteria evaluated? }\end{array}$ & BR-11 & & & \\
\hline
\end{tabular}




\begin{tabular}{|c|c|c|c|c|c|c|}
\hline & \multicolumn{2}{|r|}{ NQA-1 Basic Requirements Checklist } & Ref. & Yes & No & Notes \\
\hline \multirow[t]{2}{*}{12.0} & \multicolumn{2}{|c|}{ Control of Measuring and Test Equipment } & \multirow[b]{2}{*}{ BR-12 } & & & \\
\hline & 12.1 & $\begin{array}{l}\text { Are tools, gauges, instruments, and other measuring and } \\
\text { test equipment used for activities affecting quality } \\
\text { controlled, and at specified periods calibrated and adjusted } \\
\text { to maintain accuracy within required limits? }\end{array}$ & & & & \\
\hline \multirow[t]{3}{*}{13.0} & \multicolumn{2}{|c|}{ Handling, Storage, and Shipping } & \multirow[b]{2}{*}{ BR-13 } & & & \\
\hline & 13.1 & $\begin{array}{l}\text { Does the supplier have the necessary measures to assure } \\
\text { that handling, storage, cleaning, packaging, shipping, and } \\
\text { preservation of items is controlled to prevent damage or loss } \\
\text { and to minimize deterioration? }\end{array}$ & & & & \\
\hline & 13.2 & $\begin{array}{l}\text { Is the handling, storage, and shipping of items conducted in } \\
\text { accordance with, established work and inspection } \\
\text { instruction, drawing, specification, shipping instructions, or } \\
\text { other pertinent documents or procedures? }\end{array}$ & BR-13 & & & \\
\hline \multirow[t]{4}{*}{14.0} & \multicolumn{2}{|c|}{ Inspection, Test and Operating Status } & & & & \\
\hline & 14.1 & $\begin{array}{l}\text { The status of inspection and test activities shall be identified } \\
\text { either on the items or in documents traceable to the items? }\end{array}$ & BR-14 & & & \\
\hline & 14.2 & $\begin{array}{l}\text { Where it is necessary to assure that required inspections and } \\
\text { tests are performed, and to assure that items which have not } \\
\text { passed the required inspections and tests are not } \\
\text { inadvertently installed, used, or operated, the status shall be } \\
\text { maintained through indicators, such as physical location and } \\
\text { tags, markings, shop travelers, stamps, inspection records, } \\
\text { or other suitable means? }\end{array}$ & BR-14 & & & \\
\hline & 14.3 & $\begin{array}{l}\text { Has the authority of application and removal of tags, } \\
\text { markings, labels, and stamps been documented? }\end{array}$ & BR-14 & & & \\
\hline \multirow[t]{7}{*}{15.0} & \multicolumn{2}{|c|}{ Control of Nonconforming Items } & \multirow{7}{*}{ BR-15 } & & & \\
\hline & 15.1 & $\begin{array}{l}\text { Are the items that do not conform to specified } \\
\text { requirements controlled to prevent inadvertent installation } \\
\text { or use, and do such controls provide for: }\end{array}$ & & & & \\
\hline & & 15.1.1 identification, & & & & \\
\hline & & 15.1.2 documentation, & & & & \\
\hline & & 15.1.3 evaluation, & & & & \\
\hline & & 15.1.4 segregation (when practical), & & & & \\
\hline & & $\begin{array}{l}\text { 15.1.5 disposition of nonconforming items, and } \\
\text { notification to affected organizations? }\end{array}$ & & & & \\
\hline \multirow[t]{3}{*}{16.0} & \multicolumn{2}{|c|}{ Corrective Action } & & & & \\
\hline & 16.1 & Does the supplier's program provide that: & BR-16 & & & \\
\hline & & $\begin{array}{l}\text { 16.1.1 conditions adverse to quality shall be identified } \\
\text { promptly and corrected as soon as practical to } \\
\text { preclude repetition, }\end{array}$ & & & & \\
\hline
\end{tabular}




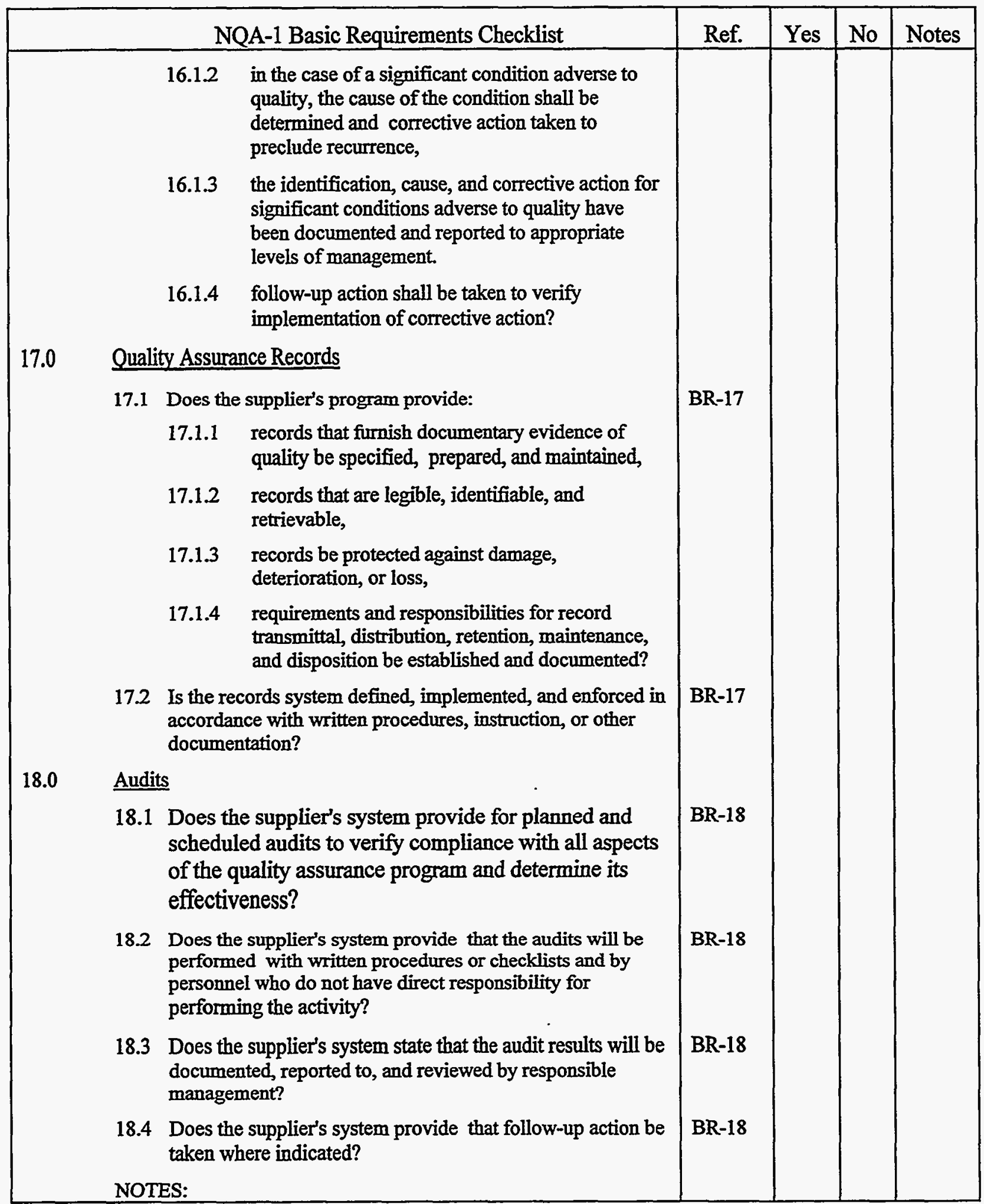

